Marquette University

e-Publications@Marquette

Civil and Environmental Engineering Faculty

Research and Publications

Civil and Environmental Engineering,

Department of

7-2019

Ion exchange nutrient recovery from anaerobic membrane

bioreactor permeate

Patrick Mullen

Kaushik Venkiteshwaran

Daniel Zitomer

Brooke K. Mayer

Follow this and additional works at: https://epublications.marquette.edu/civengin_fac

Part of the Civil Engineering Commons 


\title{
lon exchange nutrient recovery from anaerobic membrane bioreactor permeate
}

\author{
Patrick Mullen, ${ }^{\dagger}$ Kaushik Venkiteshwaran, ${ }^{*}$ (D) Daniel H. Zitomer, ${ }^{\star}$ Brooke K. Mayer ${ }^{\star}$ (D)
}

Department of Civil, Construction and Environmental Engineering, Marquette University, Milwaukee, Wisconsin

Received 30 November 2018; Revised 4 February 2019; Accepted 5 February 2019

Xylem Corporation

Additional Supporting Information may be found in the online version of this article.

Correspondence to: Brooke K. Mayer, Department of Civil, Construction and Environmental Engineering, Marquette University, Milwaukee, WI.

Email: Brooke.Mayer@marquette.edu

${ }^{\dagger}$ Present address: CNP - Technology Water and Biosolids Corporation, Kenosha, Wisconsin

*WEF Member/Fellow

Published online 1 March 2019 in Wiley Online Library (wileyonlinelibrary.com)

DOI: $10.1002 /$ wer.1080

(C) 2019 Water Environment Federation

\section{- Abstract}

Nutrient recovery from municipal wastewater was evaluated using anion exchange media loaded with hydrated ferric oxide (HFO) and copper $\left(\mathrm{Cu}^{2+}\right)$ (Dow-HFO-Cu resin) to selectively capture phosphate, followed by clinoptilolite for ammonium removal and recovery. Nutrients were concentrated in the regenerants and recovered as precipitated struvite. Media exchange capacity after multiple ion exchange cycles was determined using permeate from an anaerobic membrane bioreactor (AnMBR) treating synthetic or actual municipal wastewater from a full-scale water reclamation facility. Regeneration through five ion exchange cycles using relatively low concentration regenerant solution $(2 \% \mathrm{NaCl}$ and $0.5 \% \mathrm{NaOH})$ resulted in the highest phosphate exchange capacity and phosphate recovery. This regenerant also provided the most consistent ammonium recovery. Column tests treating AnMBR permeate were performed over five ion exchange cycles; Dow-HFO-Cu resin exchange capacities ranged from 1.6 to $2.8 \mathrm{mg} \mathrm{PO}_{4}-\mathrm{P} / \mathrm{g}$ dry media. A maximum of $94 \%$ of the removed phosphate was recovered during regeneration. The rate and extent of regeneration was insensitive to regenerant salt concentrations in the range investigated. Precipitation using a mixture of the spent regeneration brines from the Dow-HFO-Cu resin and clinoptilolite columns produced low molar ratios of $\mathrm{Mg}_{\mathrm{NH}}: \mathrm{PO}_{4}$, suggesting that the recovered product was not pure struvite. (c) 2019 Water Environment Federation

\section{- Practitioner points}

- Ion exchange-precipitation for the removal and recovery of $\mathrm{PO}_{4}^{3-}$ and $\mathrm{NH}_{4}^{+}$from AnMBR permeate is a promising technology.

- $2 \% \mathrm{NaCl}+0.5 \% \mathrm{NaOH}$ regeneration solution provided the most consistent exchange performance for both phosphate and ammonium recovery.

- Regenerated Dow-HFO-Cu resin exchange capacity was consistently less than the virgin resin, likely due to copper leaching during regeneration.

- Molar ratios in the precipitates suggested that the precipitated material was not pure struvite.

\section{- Key words}

ammonium; clinoptilolite; hydrated ferric oxide (HFO); phosphate; phosphorus; struvite; wastewater; zeolite

\section{INTRODUCTION}

THE increasing global population relies on intensified crop production to meet demands for food supply (Cordell, Rosemarin, Schröder, \& Smit, 2011; McCarty, Bae, \& Kim, 2011). The phosphorus applied as a fertilizer in many commercial agricultural settings is commonly obtained through excavation of finite phosphate rock reserves. As demand for crop production continues, these reserves are increasingly depleted, thereby enhancing interest in "mining" municipal wastewaters as an alternative source of phosphorus and other valuable resources (Mayer et al., 2016; McCarty et al., 2011).

Typical water resource recovery facilities process a continuous wastewater flow containing both phosphorus and nitrogen, thereby providing a supply of recoverable nutrients. Multiple treatment techniques are currently used to reduce the concentration of both phosphate $\left(\mathrm{PO}_{4}{ }^{3-}\right)$ and ammonium $\left(\mathrm{NH}_{4}{ }^{+}\right)$in wastewater effluents 
to help reduce the risks of eutrophication in receiving waters (Morse, Brett, Guy, \& Lester, 1998). However, most conventional nutrient removal methods do not yield recoverable, reusable nutrients (Rittmann, Mayer, Westerhoff, \& Edwards, 2011).

Ion exchange offers one approach to both remove and recover nutrients by interchanging ions of like valences attached to a solid phase medium. Once all available exchange sites on the medium are depleted, the process can be reversed through the use of a regenerant brine solution, enabling capture of the removed ions in a concentrated stream. The brine can then be used to chemically precipitate recoverable products such as struvite. Struvite $\left(\mathrm{MgNH}_{4} \mathrm{PO}_{4} \cdot 6 \mathrm{H}_{2} \mathrm{O}\right)$ is an inorganic mineral that can precipitate in the presence of high ion concentrations (de-Bashan \& Bashan, 2004) and is considered a slow release fertilizer for agriculture (Le Corre, Valsami-Jones, Hobbs, \& Parsons, 2005).

Selective removal of a targeted ion over other competing ions is essential for effective recovery, but can be difficult to achieve with traditionally available media (Petruzzelli, Dell'Erba, Liberti, Notarnicola, \& Sengupta, 2004). For example, polymeric anion exchangers lack phosphate selectivity and affinity (Sengupta \& Pandit, 2011). However, research using metal-ligand structures on synthetic polymeric exchange media has demonstrated improved selectivity of phosphates over the competing anions present in wastewaters (Blaney, Cinar, \& SenGupta, 2007; Sengupta, 2013). The exchange media developed by Sengupta and Pandit (2011) loads hydrated iron (III) oxide $\left(\mathrm{FeOOH}\right.$, abbreviated as HFO) and copper $\left(\mathrm{Cu}^{2+}\right)$ onto Dow polymeric media. The resulting Dow-HFO-Cu resin is promising for selective phosphorus removal due to the cumulative phosphate bonding with $\mathrm{HFO}$ and $\mathrm{Cu}^{2+}$, which leverages both Lewis acid-base interaction and electrostatic attraction (Sengupta \& Pandit, 2011). However, the resin's performance over time remains to be established. Additionally, the recoverability of phosphorus through the regeneration process must be assessed. Another aspect yet to be determined is performance of the Dow-HFO-Cu resin exposed to real wastewater matrices.

One wastewater matrix of increasing interest is anaerobic membrane bioreactor (AnMBR) permeate. Anaerobic conversion of wastewater organics into biogas containing methane, which can be used to generate heat and electricity, is well established for wastewater sludges and high-strength industrial wastes (McCarty et al., 2011; Speece, 2008). Since there is no mechanism for significant nutrient removal in the AnMBR process, the permeate contains soluble $\mathrm{PO}_{4}{ }^{3-}$ and $\mathrm{NH}_{4}{ }^{+}$. The presence of soluble nutrients in AnMBR permeate provides an opportunity to recover nutrients as well as energy in a coupled AnMBR/ion exchange scenario.

The specific objectives of this study were to (a) evaluate the ion exchange capacity of Dow-HFO-Cu resin and clinoptilolite media over multiple ion exchange cycles, (b) assess nutrient recovery using different regenerant brine concentrations in an effort to effectively recover nutrients using lower chemical inputs, and (c) evaluate the nutrient recovery potential in AnMBR permeate by precipitating struvite using the spent regenerant brines.

\section{MATERIALS AND METHODS}

\section{Water matrices}

To assess the performance of different regenerant solutions, initial batch tests were performed in deionized water. The water was spiked with either $\mathrm{NaH}_{2} \mathrm{PO}_{4} \bullet \mathrm{H}_{2} \mathrm{O}$ or $\mathrm{NH}_{4} \mathrm{Cl}$ to yield $30 \mathrm{mg} / \mathrm{L} \mathrm{PO}_{4}-\mathrm{P}$ for Dow-HFO-Cu resin tests or $78 \mathrm{mg} / \mathrm{L}$ $\mathrm{NH}_{4}-\mathrm{N}$ for clinoptilolite tests.

After batch testing, continuous-flow column testing was conducted using two different AnMBR permeate waters: (a) permeate from a laboratory-scale AnMBR treating synthetic primary effluent wastewater (Seib, Berg, \& Zitomer, 2016) and (b) permeate from the same laboratory-scale AnMBR treating municipal wastewater primary effluent collected from the South Shore Water Reclamation Facility, Oak Creek, WI, as described by Seib et al. (2016). Pertinent parameters for the two AnMBR permeates are shown in Table 1.

\section{Ion exchange media}

Dow-HFO-Cu resin was prepared by loading $\mathrm{Cu}^{2+}$ and HFO metals on a commercial ion exchange resin (Dowex M4195, Dow Chemical Company, Midland, MI) according to the protocol of Sengupta and Pandit (2011). The resin's bulk density was $673 \mathrm{~g} / \mathrm{L}$, and its ion exchange capacity was $1 \mathrm{meq} / \mathrm{mL}$ (Sengupta \& Pandit, 2011). Scanning electron microscopy was used to quantify the particle size range as $300-700 \mu \mathrm{m}$ (Figure 5), in agreement with that reported by Sengupta and Pandit (2011), 297-841 $\mu \mathrm{m}$ (average $=570 \mu \mathrm{m})$.

Clinoptilolite media (St. Cloud Zeolite, Tucson, AZ) was preconditioned by washing it to remove fine particles, followed by mixing $30 \mathrm{~g}$ of media with $1 \% \mathrm{NaCl}$ solution for 2 days, and finally rinsing and drying for $24 \mathrm{hr}$ at $103^{\circ} \mathrm{C}$ (Hedström, 2001; Sengupta, 2013).

Table 1. AnMBR influent wastewater parameters

\begin{tabular}{|c|c|c|c|c|}
\hline \multirow[b]{2}{*}{ CONSTITUENT } & \multicolumn{2}{|c|}{ SYNTHETIC PRIMARY EFFLUENT } & \multicolumn{2}{|c|}{ MUNICIPAL PRIMARY EFFLUENT } \\
\hline & $\begin{array}{l}\text { AVERAGE } \pm 1 \text { STANDARD } \\
\text { DEVIATION }(\mathrm{MG} / \mathrm{L})\end{array}$ & $N$ & $\begin{array}{l}\text { AVERAGE } \pm 1 \text { STANDARD } \\
\text { DEVIATION }(\mathrm{MG} / \mathrm{L})\end{array}$ & $N$ \\
\hline $\mathrm{PO}_{4}-\mathrm{P}$ & $4.6 \pm 0.2$ & 14 & $4.9 \pm 0.7$ & 15 \\
\hline $\mathrm{NH}_{4}-\mathrm{N}$ & $38 \pm 2.7$ & 14 & $34 \pm 5.9$ & 15 \\
\hline $\mathrm{SO}_{4}{ }^{2-}$ & $16 \pm 2.5$ & 3 & $56 \pm 10$ & 3 \\
\hline $\mathrm{Cl}^{-}$ & $462 \pm 72$ & 3 & $536 \pm 25$ & 3 \\
\hline $\mathrm{BOD}_{5}$ & $2.5 \pm 1.3$ & 73 & $6.0 \pm 3.3$ & 11 \\
\hline
\end{tabular}




\section{Batch tests}

To assess the nutrient removal capacity of ion exchange media over multiple ion exchange cycles, batch tests were conducted in triplicate vials prepared with $50 \mathrm{~mL}$ of nutrientspiked deionized water and $10 \mathrm{~g} / \mathrm{L}$ of the respective exchange media. The vials were sealed and continuously mixed for $48 \mathrm{hr}$ using a rotator mixer (Roto Torque ${ }^{\mathrm{m}}$, Cole-Parmer Instrument Company) to ensure time to reach equilibrium, as determined in preliminary tests (Figure S1.1 of the Supporting Information [SI]). The supernatant was then analyzed for $\mathrm{PO}_{4}-\mathrm{P}$ or $\mathrm{NH}_{4}-\mathrm{N}$, and the exchange capacity was calculated by dividing the mass of ions adsorbed by the mass of the media.

After the removal cycle, the remaining solution was decanted from the exhausted media, which was then rinsed with deionized water, and regeneration was conducted to desorb and recover $\mathrm{PO}_{4}{ }^{3-}$ or $\mathrm{NH}_{4}{ }^{+}$using various regenerant solutions (Table 2). Solutions including those reported by Sengupta (2013) were tested in order to evaluate the nutrient desorption and regenerated media sorption capacity. For regeneration tests, $50 \mathrm{~mL}$ of regeneration solution was added to each vial containing spent media; vials were then sealed and mixed for $4 \mathrm{hr}$, as described by Williams (2013). After regeneration, $\mathrm{PO}_{4}-\mathrm{P}$ or $\mathrm{NH}_{4}-\mathrm{N}$ concentration in the supernatant regeneration solution was measured and the media were prepared for the next exchange cycle by rinsing with deionized water. Five sequential removal and regeneration cycles were completed to evaluate media exchange capacity after multiple ion exchange cycles.

\section{Column tests}

Ion exchange. Column tests were performed using two sequential fixed-bed columns containing Dow-HFO-Cu resin and clinoptilolite, respectively. Exchange media $(15 \mathrm{~mL})$ was packed in a $300-\mathrm{mm}$ long, $10-\mathrm{mm}$ diameter glass column (AdjustaChrom \#11, Ace Glass Inc., Vineland, NJ). AnMBR permeate from the synthetic or real primary effluent was pumped through the columns at $2 \mathrm{~L} /$ day to achieve 5.5 bed volumes $(\mathrm{BV}) / \mathrm{h}$ and an empty bed contact time (EBCT) of 10.8 min using a peristaltic pump (Masterflex ${ }^{\circ} \mathrm{C} / \mathrm{L}$, ColeParmer, USA). Effluent from the Dow-HFO-Cu resin column was collected in a continuously stirred $2-\mathrm{L}$ container for use as influent for the clinoptilolite column. Effluent samples from

Table 2. Regenerant solutions tested in batch tests

\begin{tabular}{|lllll|}
\hline ION EXCHANGE & TARGET & $\%$ & $\%$ & \\
MEDIA & NUTRIENT & NACL & NAOH & PH \\
\hline Dow-HFO-Cu & $\mathrm{PO}_{4}$-P & 2.5 & 2 & 13 \\
& & 1.5 & 1 & 12 \\
& & 1 & 0.5 & 11 \\
& & 2 & 0.5 & 11 \\
& & 1 & 2 & 13 \\
Clinoptilolite & $\mathrm{NH}_{4}-\mathrm{N}$ & 2 & 0.5 & 11 \\
& & 4 & 0.5 & 11 \\
& & 6 & 0.5 & 11 \\
\hline
\end{tabular}

each column were collected every two hours using a two-way diverter solenoid valve and fraction collector (CF-1, Spectrum Chromatography, Houston, TX). When the column was exhausted, indicated by effluent concentrations reaching $85 \%$ of the influent concentration, the removal test was stopped and the media was rinsed with 5 to $10 \mathrm{BV}$ of deionized water in preparation for regeneration.

Regeneration. The regeneration solution used in column tests was determined as the regenerant with the most $\mathrm{PO}_{4}-\mathrm{P}$ recovery and least media attrition in subsequent ion exchange cycles during batch tests. Column regeneration was performed by feeding this regenerant through the respective column at $2 \mathrm{~L} /$ day. Effluent regeneration samples were collected every 30 min for $\mathrm{PO}_{4}-\mathrm{P}$ and $\mathrm{NH}_{4}-\mathrm{N}$ analysis. The effluent regenerant from the columns was collected in bulk for subsequent struvite precipitation tests. Regeneration was conducted until effluent $\mathrm{PO}_{4}-\mathrm{P}$ or $\mathrm{NH}_{4}-\mathrm{N}$ concentrations dropped below $10 \mathrm{mg} / \mathrm{L}$, beyond which point a much larger volume of regeneration solution would be required to desorb a smaller fraction of the ions (Williams \& Mayer, 2013; Williams, Zitomer, \& Mayer, 2015). After regeneration, 5 to $10 \mathrm{BV}$ of deionized water was pumped through the column to remove remaining regenerant solution and to prepare the media for another subsequent removal cycle.

The total mass of desorbed $\mathrm{PO}_{4}-\mathrm{P}$ or $\mathrm{NH}_{4}-\mathrm{N}$ during regeneration was calculated by fitting multiple trend lines to the effluent concentration curve, plotted with respect to time, using Microsoft Excel. The resulting equations were integrated to determine the total desorbed nutrient mass $\left(\mathrm{PO}_{4}-\mathrm{P}\right.$ or $\mathrm{NH}_{4}-\mathrm{N}$ ). Figure $\mathrm{S} 4.2$ shows an example of this approach implemented to assess $\mathrm{NH}_{4}-\mathrm{N}$ recovery during zeolite column regeneration.

\section{Struvite precipitation tests}

Effluent regenerant brine from the column tests was used for subsequent struvite precipitation testing. Using the regeneration solutions recovered from the first cycle of anion and cation exchange, preliminary screening was conducted to determine the $\mathrm{pH}(8,8.7$, or 9 , adjusted using $0.1 \mathrm{M} \mathrm{HCl}$ solution) and the $\mathrm{Mg}^{2+}: \mathrm{PO}_{4}{ }^{3-}$ ratio $(1: 1-1.3: 1)$ that resulted in the greatest $\mathrm{PO}_{4}-\mathrm{P}$ precipitation. These conditions were then used in all subsequent tests.

Initial concentrations of $\mathrm{PO}_{4}{ }^{3-}$ and $\mathrm{NH}_{4}{ }^{+}$in the column regenerants were measured to calculate stoichiometric molar ratios of $\mathrm{PO}_{4}{ }^{3-}, \mathrm{NH}_{4}^{+}$, and $\mathrm{Mg}^{2+}$. Since $\mathrm{Mg}^{2+}$ concentrations are typically low in municipal wastewater, $12.5 \mathrm{~g} \mathrm{MgCl}_{2} \bullet 6 \mathrm{H}_{2} \mathrm{O}$ was mixed with $1 \mathrm{~L}$ of deionized water, which was added to the mixed regenerants to target the desired molar ratios among the ions. After mixing, each solution was allowed to settle for 30 minutes and was then filtered through a $0.45-\mu \mathrm{m}$ glass fiber filter followed by analysis of the filtrate for $\mathrm{PO}_{4}-\mathrm{P}, \mathrm{NH}_{4}-\mathrm{N}$, and $\mathrm{Mg}^{2+}$

\section{Analytical methods and data analysis}

All $\mathrm{PO}_{4}$-P concentrations were analyzed using the PhosVer 3 Phosphate Reagent powder pillow (Hach Company, 
Loveland, CO) spectrophotometric method adapted from the standard ascorbic acid method 4500-PE (APHA et al., 2012). $\mathrm{NH}_{4}$-N concentrations were analyzed using the phenate method, standard method $4500-\mathrm{NH}_{3} \mathrm{~F}$. Total concentrations of $\mathrm{Mg}^{2+}, \mathrm{Ca}^{2+}, \mathrm{Al}^{3+}, \mathrm{Fe}^{2+}$, and $\mathrm{Cu}^{2+}$ were determined by digesting $10 \mathrm{~mL}$ of solution using the standard nitric acid digestion method 3030 E (APHA; AWWA; WEF, 2012). To assess the soluble fractions, a portion of the samples was filtered through $0.45 \mu \mathrm{m}$ PES membrane filters (Sigma-Aldrich, St. Louis, MO) prior to nitric acid digestion. Digested samples were analyzed using inductively coupled plasma-mass spectrometry (7700 Series, Agilent Technologies, Santa Clara, $\mathrm{CA})$. Anion concentrations including $\mathrm{PO}_{4}{ }^{3-}, \mathrm{SO}_{4}{ }^{2-}$, and $\mathrm{Cl}^{-}$ were determined using ion chromatography (Dionex ICS1100, Thermo Fisher Scientific, Waltham, MA). BOD 5 was determined via standard method 5210 B (APHA; AWWA; WEF, 2012).
Dow-HFO-Cu resin analysis before and after regeneration using SEM and EDS. Scanning electron microscope (SEM) and energy dispersive X-ray spectroscopy (EDS) analyses were conducted to assess the effects of media regeneration on the structure and elemental composition of the Dow-HFO$\mathrm{Cu}$ media. The SEM and EDS analyses were conducted using samples of virgin and regenerated Dow-HFO-Cu media. The regenerated Dow-HFO-Cu media was from batch tests (Section 2.3) following one regeneration cycle using $2 \%$ $\mathrm{NaCl}+0.5 \% \mathrm{NaOH}$ regenerant.

The spherical Dow-HFO-Cu media samples were collected on double-sided carbon conducting tape and were then sputter coated with approximately $20 \mathrm{~nm}(200 \AA$ Á) of gold-palladium to make them conductive. The specimens were examined and photographed using a JEOL JSM 6510LV SEM operated at $20 \mathrm{kV}$ with a working distance of $20 \mathrm{~mm}$ and a spot size of 60 . Scanning electron micrographs were obtained for one virgin
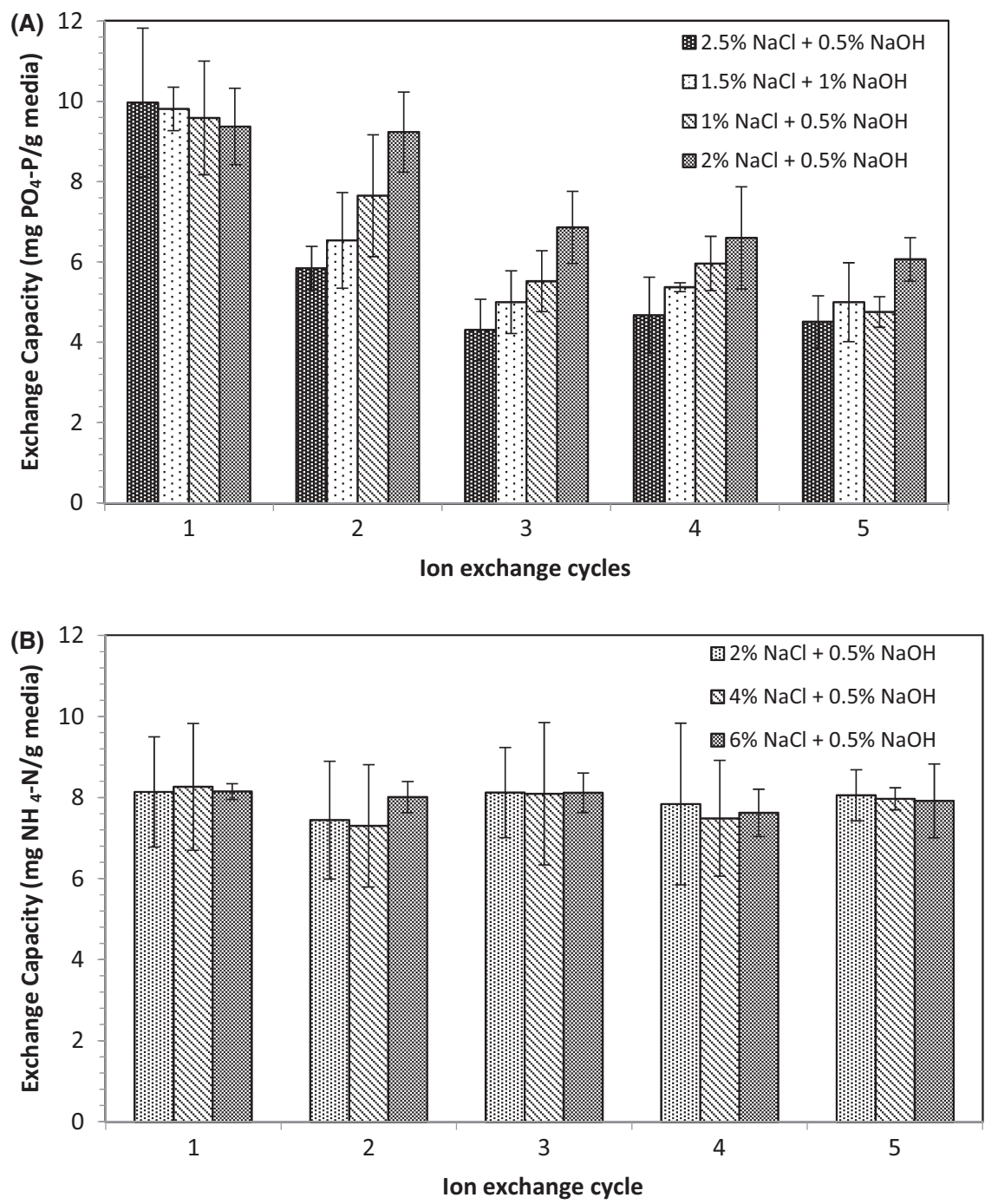

Figure 1. Batch tests of the exchange capacity of (a) $\mathrm{PO}_{4}-\mathrm{P}$ using Dow-HFO-Cu resin and (b) $\mathrm{NH}_{3}-\mathrm{N}$ using clinoptilolite over five ion exchange/regeneration cycles using different regenerant solutions. Tests were performed in deionized water spiked with either $30 \mathrm{mg} / \mathrm{L}$ $\mathrm{PO}_{4}-\mathrm{P}$ for Dow-HFO-Cu resin tests or $78 \mathrm{mg} / \mathrm{L} \mathrm{NH}_{4}-\mathrm{N}$ for clinoptilolite tests. All bars represent average results from triplicate experiments, with error bars depicting \pm 1 standard deviation. 
and one regenerated Dow-HFO-Cu sphere at 150X and 500X. EDS spectra were obtained with a Fisher Scientific NORAN System 7 spectrum analyzer from areas at the center of each sphere at a magnification of 500X using an acquisition time of $100 \mathrm{~s}$. The EDS spectra were obtained for three different virgin and regenerated Dow-HFO-Cu resin beads, and the spectra were quantitatively analyzed using the filter without standards and a Phi-Rho-Z correction. The output K-ratio values, which is the ratio of the intensity (number of X-ray counts) for an element of interest in the sample to the intensity for the standard assigned to that element, were used as a qualitative measure of changes in the elemental composition of the regenerated DowHFO-Cu media.

Data analysis. One-way ANOVA and Tukey's multiple comparison post hoc statistical analyses $(\alpha \leq 0.05)$ were used to test for statistical differences using commercial software (Prism, Graph Pad Software, La Jolla, CA).

\section{RESULTS AND DISCUSSION}

\section{Batch tests}

The exchange capacity of virgin Dow-HFO-Cu resin was between 9 and $10 \mathrm{mg} \mathrm{PO}_{4}-\mathrm{P} / \mathrm{g}$ media (Figure 1a), whereas a capacity of $15 \mathrm{mg} \mathrm{PO}_{4}$-P/g media was estimated by Sengupta and Pandit (2011). The resin's exchange capacity significantly declined after regeneration (Figure 1a, Table S2.1 of the Supporting Information). The largest exchange capacity decrease was generally observed after the first regeneration cycle, suggesting that $\mathrm{PO}_{4}{ }^{3-}$ exchange sites may have been stripped from the surface of the Dow-HFO-Cu media. For example, alkaline solutions are used in regeneration to break the strong bonds between the phosphates and ligands, but high $\mathrm{pH}$ can potentially strip the exchange media of the $\mathrm{Cu}^{2+}$ and HFO, thus eliminating exchange sites for subsequent removal cycles.

Clinoptilolite exchange capacity was not significantly influenced by the number of regeneration cycles over the range tested
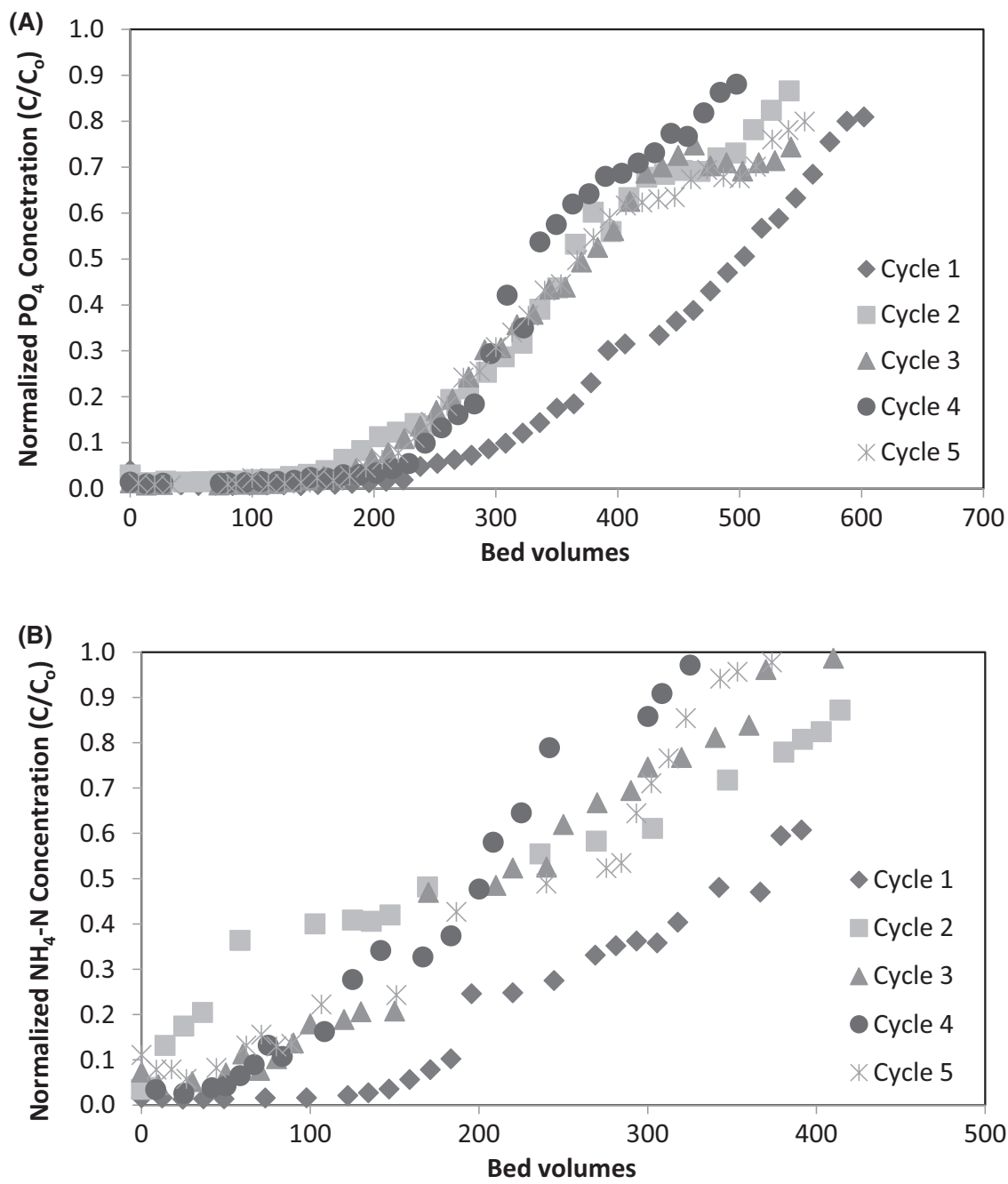

Figure 2. Breakthrough curves for (a) phosphate for the Dow-HFO-Cu exchange media and (b) ammonium for the zeolite media treating synthetic wastewater AnMBR permeate. All data points are single measurements of column effluent normalized to the tested water influent nutrient concentration. 
(Figure $1 \mathrm{~b}$ ). The capacity ranged from 7 to $8 \mathrm{mg} \mathrm{NH}_{4}$ - N/g media over five ion exchange cycles. Of the three regeneration solutions tested, the solution with $2 \% \mathrm{NaCl}$ and $0.5 \% \mathrm{NaOH}$ provided the most consistent performance, similar to the Dow-HFO-Cu resin $(p<0.05)$ (Table S2.2 of the Supporting information).

Regeneration solutions containing $2.5 \% \mathrm{NaCl}+2 \% \mathrm{NaOH}$ (suggested by Sengupta (2013)) and $2 \% \mathrm{NaCl}+0.5 \% \mathrm{NaOH}$ resulted in the least exchange capacity loss after regeneration. Beyond three ion exchange cycles, no significant difference in exchange capacities among sequential ion exchange cycles was observed $(p<0.05)$ when using the two regeneration solutions. A complete summary of the statistical analyses is provided in Table S2.1 of the Supporting information. In comparison with the $2.5 \% \mathrm{NaCl}+2 \% \mathrm{NaOH}$ regenerant, the lower $\mathrm{pH}$ regenerant $(2 \% \mathrm{NaCl}+0.5 \% \mathrm{NaOH})$ achieved a higher stabilized exchange capacity over five ion exchange cycles, with a final exchange capacity of $6.5 \mathrm{mg} \mathrm{PO}_{4} / \mathrm{g}$ media. This lower $\mathrm{pH}$ ostensibly caused less ligand stripping from the polymer, thereby better preserving media capacity over sequential ion exchange cycles.

\section{Column tests}

Exchange capacity over multiple ion exchange cycles. Operation of ion exchange processes as a continuous-flow packed bed is a more realistic scenario for implementation. Thus, following batch experiments to gauge performance, laboratory-scale column tests were performed. A normalized effluent phosphate concentration $\left(\mathrm{C} / \mathrm{C}_{\mathrm{o}}\right)$ of less than 0.1 was maintained for over $300 \mathrm{BV}$ during the initial removal cycle (Figure 2a). However, as observed in batch testing, the greatest decrease in removal performance occurred between ion exchange cycles 1 and 2, during which the second removal cycle achieved $\mathrm{C} / \mathrm{C}_{\mathrm{o}} \leq 0.1$ through only $190 \mathrm{BV}$. All subsequent ion exchange cycles were characterized by breakthrough within the range of BV observed in the first two ion exchange cycles.

Phosphate exchange capacities were calculated using data from each ion exchange cycle (Figure $3 a)$. The exchange capacities of Dow-HFO-Cu media treating synthetic wastewater AnMBR permeate ranged from 1.6 to $2.8 \mathrm{mg}-\mathrm{PO}_{4}-\mathrm{P} / \mathrm{g}$ during the fifth and first cycle, respectively. For municipal primary effluent AnMBR permeate, Dow-HFO-Cu media exchange capacities were 1.6 to $2.6 \mathrm{mg}-\mathrm{PO}_{4}-\mathrm{P} / \mathrm{g}$ media during the fourth and first cycle, respectively. The largest exchange capacity reductions occurred during column testing between the first and second ion exchange cycles, with $22 \%$ and $24 \%$ decreases for the synthetic wastewater and primary effluent AnMBR permeates, respectively. Following the initial exchange and regeneration cycle, the average exchange capacity for both tested AnMBR permeates was $2 \mathrm{mg} \mathrm{PO}_{4}-\mathrm{P} / \mathrm{g}$ media. For influent water containing $5 \mathrm{mg} \mathrm{PO}_{4}-\mathrm{P} / \mathrm{L}$, this translates to $0.4 \mathrm{~L}$ water treated per gram of media. The column capacities were significantly less than those observed during batch tests, suggesting that the column hydrodynamics influenced exchange capacity measurements.

Fixed-bed clinoptilolite column tests were also completed using each AnMBR permeate to assess the exchange capacity over five ion exchange cycles (Figures $2 \mathrm{~b}$ and $3 \mathrm{~b}$ ).

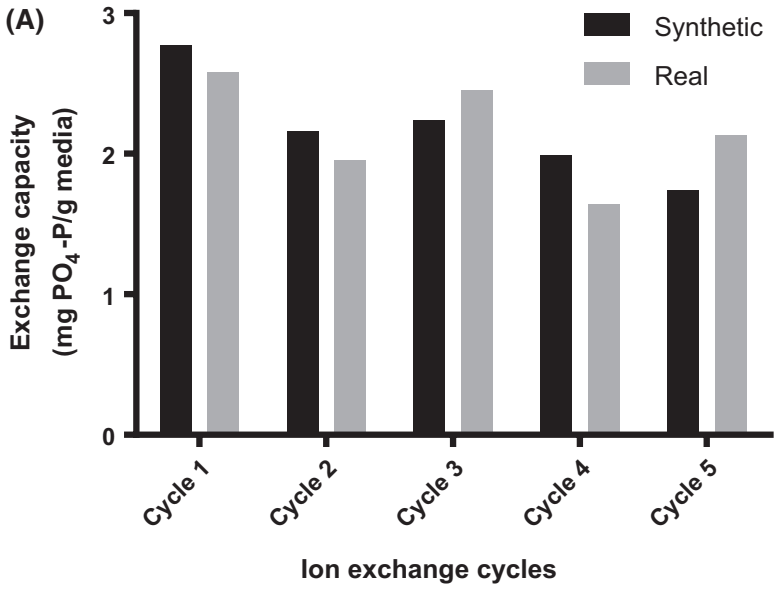

Exchange Capacity

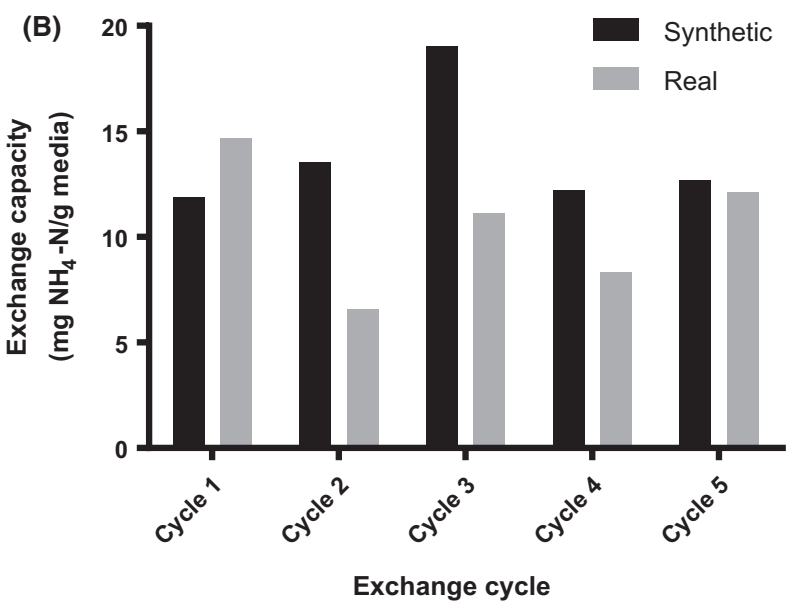

Figure 3. Exchange capacities of (a) Dow-HFO-Cu resin and (b) clinoptilolite ion exchange media in column studies testing real and synthetic AnMBR wastewater permeate.

The exchange capacities ranged from 11 to $19 \mathrm{mg}-\mathrm{NH}_{4}-\mathrm{N} / \mathrm{g}$ treating synthetic water, and 6 to $14 \mathrm{mg}-\mathrm{NH}_{4}-\mathrm{N} / \mathrm{g}$ treating primary effluent. No general relationship was discerned regarding ammonium capacity and exchange cycle under the conditions studied. Exchange capacity values exceeded those observed in batch tests, unlike the Dow-HFO-Cu media, which showed reductions in the exchange capacities for column tests compared to batch tests. Regeneration using a solution containing $2 \% \mathrm{NaCl}$ and $0.5 \% \mathrm{NaOH}$ typically resulted in less than $50 \%$ recovery of the $\mathrm{NH}_{4}-\mathrm{N}$ (Figure S4.1 in the Supporting information).

\section{Regeneration: content of recovered regenerant solutions and impact on the Dow-HFO-Cu resin} Regenerated Dow-HFO-Cu resin exchange capacity was consistently less than that of the virgin resin. Regeneration may have reduced the number of active phosphate binding sites on the Dow-HFO-Cu surface. To assess loss of the reactive sites during regeneration, metal concentrations in the regenerant solution were measured for the regenerant with the least 

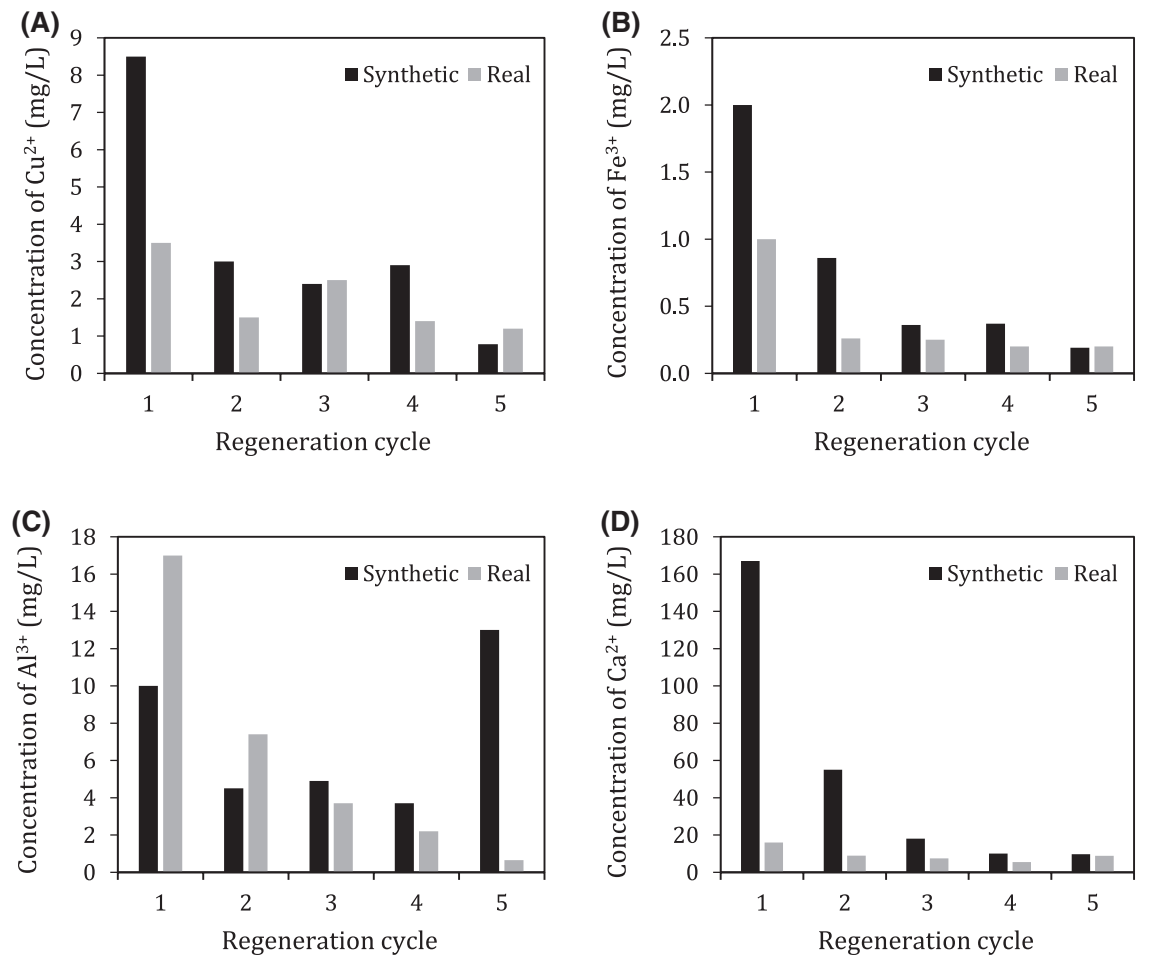

Figure 4. Concentrations of metals, (a) copper, (b) iron, (c) aluminum, and (d) calcium, in $2 \% \mathrm{NaCl}+0.5 \% \mathrm{NaOH}$ regeneration eluate of Dow-HFO-Cu exchange media using synthetic or real AnMBR wastewater permeate. Note that the scale of the $y$-axis varies in each panel.
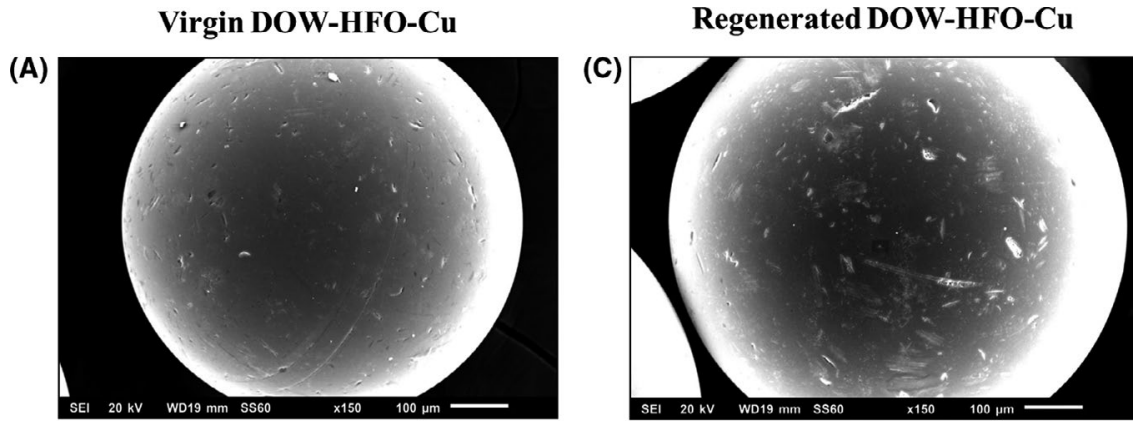

(B)

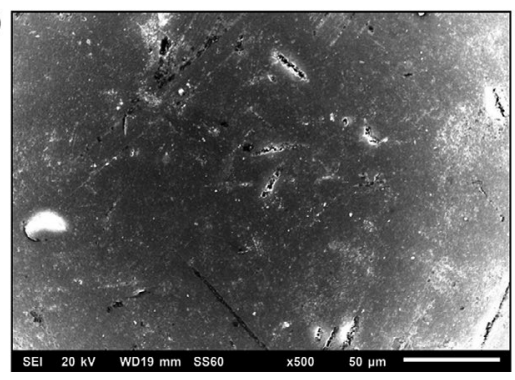

(D)

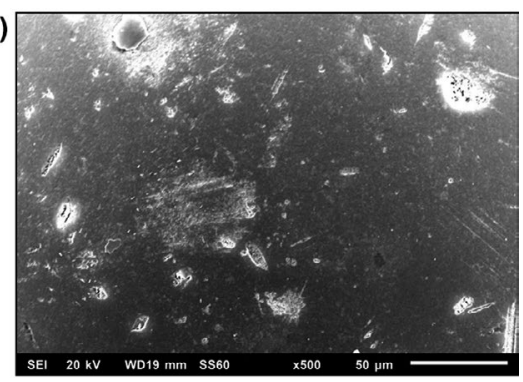

Figure 5. Scanning electron microscope (SEM) images of virgin and regenerated Dow-HFO-Cu media. (a) and (b) show 150X and 500X magnification images of one virgin Dow-HFO-Cu resin bead, respectively. (c) and (d) show 150X and 500X magnification images, respectively, of one Dow-HFO-Cu resin bead following one regeneration cycle using $2 \% \mathrm{NaCl}+0.5 \% \mathrm{NaOH}$ regenerant. The regenerated DowHFO-Cu resin bead shows numerous and larger surface indentations as compared to the virgin resin.

decrease in $\mathrm{PO}_{4}{ }^{3-}$ sorption capacity in subsequent ion exchange cycles, $2 \% \mathrm{NaCl}$ and $0.5 \% \mathrm{NaOH}$ (Figure 4).

The copper $\left(\mathrm{Cu}^{2+}\right)$ and iron $\left(\mathrm{Fe}^{3+}\right)$ complexes on DowHFO-Cu media are the intended ligands responsible for $\mathrm{PO}_{4}-\mathrm{P}$ adsorption; therefore, loss of these ions during regeneration would negatively impact exchange capacity and could also decrease struvite fertilizer value due to potential $\mathrm{Cu}^{2+}$ contamination. While the $\mathrm{Fe}^{3+}$ concentration was relatively low in 
the regeneration solution (Figure 4), significant $\mathrm{Cu}^{2+}$ leaching occurred. For column tests, the regeneration solution with the highest $\mathrm{Cu}^{2+}$ concentration was observed after the initial regeneration cycle, with concentrations of 8.5 and $3.5 \mathrm{mg} / \mathrm{L}$ (or 0.26 and $0.11 \mathrm{mg} \mathrm{Cu}^{2+}$ lost per gram of media) for synthetic wastewater and primary effluent AnMBR permeate, respectively. Batch tests demonstrated that 52 to $56 \%$ of the $\mathrm{Fe}^{3+}$ and $\mathrm{Cu}^{2+}$ in the regeneration solution were in the soluble form $(<0.45 \mu \mathrm{m})$. This correlates with the decreased exchange capacities observed between the first and second removal cycles. Additional $\mathrm{Cu}^{2+}$ leaching was also observed in all subsequent regeneration cycles, ranging from 0.8 to $3 \mathrm{mg}-\mathrm{Cu}^{2+} / \mathrm{L}$.

SEM images revealed substantial surface scratches and indentations on the Dow-HFO-Cu resin surface after the initial regeneration cycle using $2 \% \mathrm{NaCl}+0.5 \% \mathrm{NaOH}$, compared to the virgin Dow-HFO-Cu media (Figure 5). Apart from changes to the structure of the resin surface, K-ratio values from EDS analysis demonstrated a significant decrease in the resin's $\mathrm{Cu}$ content $(p<0.05)$, although no significant decrease in Fe was observed after the initial regeneration cycle (Figure 6). Results from the EDS spectral analysis correlate with the observed $\mathrm{Fe}^{3+}$ and $\mathrm{Cu}^{2+}$ concentration in the regeneration solution after the initial regeneration cycle. Together, the metal analysis of the regenerant and the resin EDS analysis indicate significant leaching of $\mathrm{Cu}^{2+}$ and moderate loss of $\mathrm{Fe}^{3+}$ complexes during DowHFO-Cu regeneration, which also correlates with the decreased exchange capacities observed. Approaches to minimize $\mathrm{Cu}^{2+}$ loss should be considered in future work using Dow-HFO-Cu exchange media. For example, a layer of conventional exchange media without $\mathrm{Cu}^{2+}$ or $\mathrm{HFO}$ at the bottom of the exchange bed can be used to capture any $\mathrm{Cu}^{2+}$ ions that may be stripped from the prepared media (Zhao \& Sengupta, 1998).

The spent regeneration solutions also contained $\mathrm{Al}^{3+}$ and $\mathrm{Ca}^{2+}$ ions that can inhibit struvite precipitation. For example, $\mathrm{Al}^{3+}$ can precipitate $\mathrm{AlPO}_{4}$, and the $\mathrm{PO}_{4}{ }^{3-}$ bound in this precipitate is largely considered to be unavailable for plant growth (Morse et al., 1998; Rittmann et al., 2011). Additionally, $\mathrm{Ca}^{2+}$ can cause precipitation of calcium phosphate that may be reused as fertilizer, but does not recover $\mathrm{NH}_{4}^{+}$along with $\mathrm{PO}_{4}{ }^{3-}$, as does struvite precipitation.

\section{Precipitated products for nutrient recovery}

Precipitation tests were performed by combining the cation and anion regeneration solutions and adding $\mathrm{MgCl}_{2} \cdot 6 \mathrm{H}_{2} \mathrm{O}$.
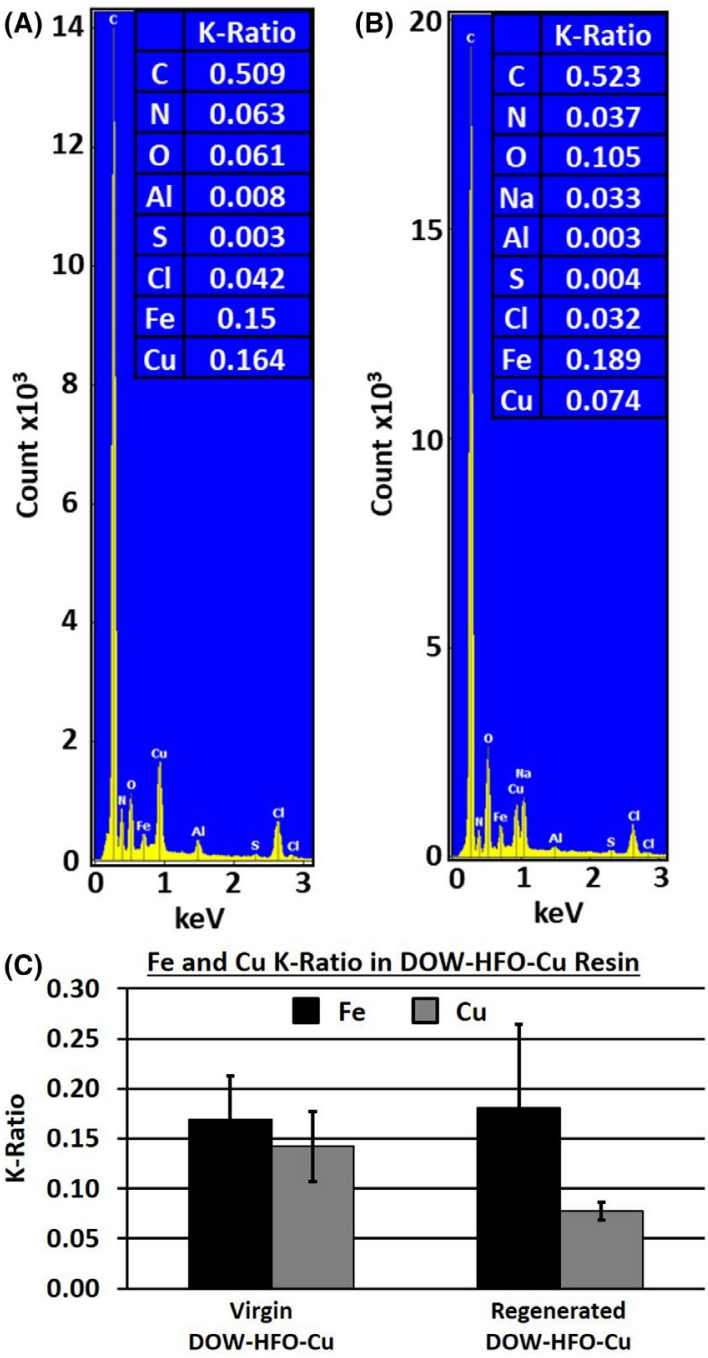

Figure 6. Energy dispersive X-ray spectroscopy (EDS) spectra and K-ratio values of virgin and regenerated Dow-HFO-Cu resin. EDS spectra are shown for (a) one virgin and (b) one regenerated Dow-HFO-Cu resin bead, along with K-ratio values of detected elements. The regenerated Dow-HFO-Cu resin underwent one regeneration cycle using $2 \% \mathrm{NaCl}+0.5 \% \mathrm{NaOH}$ regenerant. Panel (c) shows the average $\mathrm{Fe}$ and $\mathrm{Cu}$ K-ratio values observed from EDS analysis of three different virgin and regenerated Dow-HFO-Cu resin beads. The error bars represent \pm 1 standard deviation. The $\mathrm{K}$-ratio indicates a significant decrease in the Cu composition after one regeneration cycle $(p<0.05)$, whereas no significant decrease in the resin's Fe content was observed.

Table 3. Calculated molar ratios of solid precipitate from supernatant mass balance

\begin{tabular}{|c|c|c|c|c|c|c|}
\hline \multirow{2}{*}{$\begin{array}{l}\text { ION EXCHANGE } \\
\text { CYCLE }\end{array}$} & \multicolumn{3}{|c|}{ SYNTHETIC PRIMARY EFFLUENT } & \multicolumn{3}{|c|}{ MUNICIPAL PRIMARY EFFLUENT } \\
\hline & $\mathrm{MG}^{2+}$ & $\mathrm{NH}_{4}^{+}$ & $\mathrm{PO}_{4}{ }^{3-}$ & $\mathrm{MG}^{2+}$ & $\mathrm{NH}_{4}{ }^{+}$ & $\mathrm{PO}_{4}{ }^{3-}$ \\
\hline 1 & 1.1 & 0.1 & 0.4 & 0.8 & 0.1 & 0.9 \\
\hline 2 & 1.0 & 0.4 & 0.2 & 0.2 & 0.5 & 0.4 \\
\hline 3 & 0.9 & 0.5 & 0.3 & 0.5 & 0.4 & 0.2 \\
\hline 4 & 0.9 & 0.2 & 0.2 & 0.1 & 0.6 & 0.2 \\
\hline 5 & 1.2 & 0.2 & 1.0 & 0.4 & 0.9 & 0.1 \\
\hline
\end{tabular}




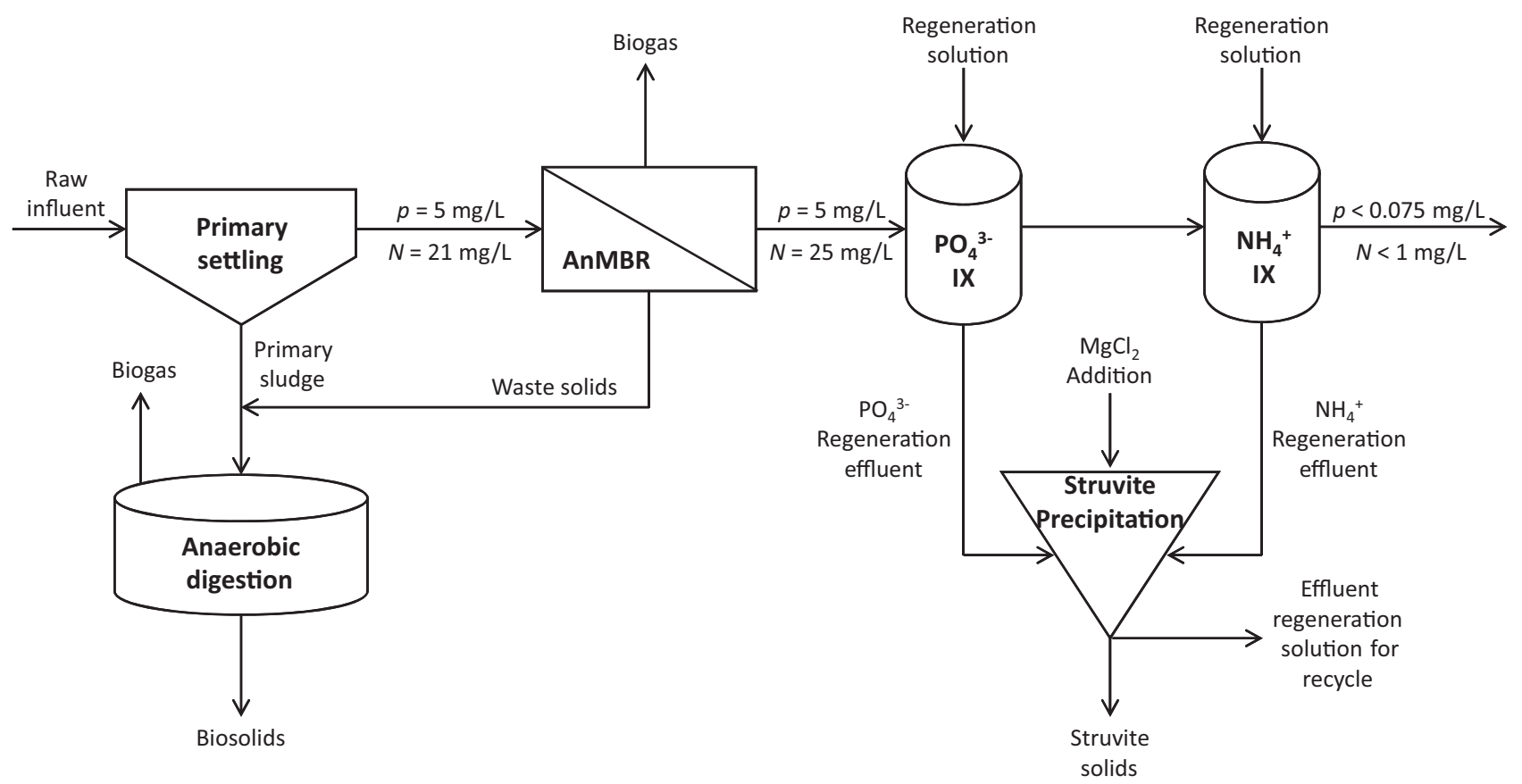

Figure 7. Nutrient recovery process diagram using results from the laboratory-scale AnMBR treating synthetic wastewater followed by ion exchange columns.

Screening tests using regeneration solutions from the first ion exchange cycle were used to determine the optimal $\mathrm{pH}$ of 8 and $1.3: 1 \mathrm{Mg}^{2+}$ to $\mathrm{PO}_{4}{ }^{3-}$ ratio for synthetic wastewater column tests (ratio of 1.1:1 for the primary effluent tests). The optimal $\mathrm{pH}$ and $\mathrm{Mg}^{2+}$ dosing ratios were chosen as they offered the largest decrease in soluble $\mathrm{PO}_{4}{ }^{3-}$ concentration during screening tests.

A mass balance was performed using supernatant from batch-style precipitation tests to determine the molar ratios in the precipitates in comparison to pure struvite (Table 3). Most of the resulting $\mathrm{NH}_{4}{ }^{+}$and $\mathrm{PO}_{4}{ }^{3-}$ molar ratios calculated from the tests were below the target range; however, two of the tests did recover $\mathrm{PO}_{4}{ }^{3-}$ and $\mathrm{Mg}^{2+}$ in the precipitated product with molar ratios close to or greater than one. $\mathrm{NH}_{4}^{+}$ratios were much lower than theoretical values, suggesting that the precipitated material was not pure struvite. Similar results were observed by Williams (2013) and could be due to the high $\mathrm{pH}$ of the regeneration solution, in which increased $\mathrm{pH}$ can convert $\mathrm{NH}_{4}{ }^{+}$ions to $\mathrm{NH}_{3}$ and carry other competing ions stripped from the exchange media into solution, thereby inhibiting struvite precipitation (Hao, Wang, van Loosdrecht, \& Hu, 2013).

\section{Conclusions}

In batch tests, the largest reduction in Dow-HFO-Cu exchange capacity was observed after the initial regeneration cycle, likely due to stripping of $\mathrm{Cu}^{2+}$ ligands. However, a consistent exchange capacity of $6.5 \mathrm{mg} \mathrm{PO}_{4}$-P/g Dow-HFO-Cu was achieved beyond three ion exchange cycles using a regeneration solution of $2 \% \mathrm{NaCl}+0.5 \% \mathrm{NaOH}$. This regeneration solution also provided the most consistent $\mathrm{NH}_{4}-\mathrm{N}$ recovery using clinoptilolite. Use of the same solution for both anion and cation regeneration offers operational benefits.

Column tests also demonstrated decreases in exchange capacities after initial regeneration and offered lower overall phosphate removal capacity compared to batch tests, at 1.6 to $2.8 \mathrm{mg}-\mathrm{PO}_{4}-\mathrm{P} / \mathrm{g}$ Dow-HFO-Cu. Similarities in exchange capacities using the synthetic and actual AnMBR permeates suggest that comparable performance could be achieved treating variable quality AnMBR permeates. Although leaching of copper metals was observed in each regeneration cycle, the majority of the phosphate entering the columns was recovered $(94 \%$ and $79 \%$ recovery of removed mass of $\mathrm{PO}_{4}-\mathrm{P}$ for the synthetic and real wastewater permeates, respectively).

Column tests showed removal and recovery of $\mathrm{NH}_{4}{ }^{+}$using clinoptilolite; however, less than $50 \%$ of the removed fraction of $\mathrm{NH}_{4}-\mathrm{N}$ was recovered in nearly all regeneration experiments. Thus, future improvements in regeneration conditions are desirable to achieve greater desorption of captured $\mathrm{NH}_{4}{ }^{+}$during regeneration, thereby improving subsequent exchange capacities. Precipitation tests using column regenerants indicated that products other than pure struvite were being precipitated, as a 1:1:1 molar ratio of $\mathrm{Mg}: \mathrm{NH}_{4}: \mathrm{PO}_{4}$ was not consistently achieved.

To provide an alternate, more sustainable nutrient source, ion exchange-precipitation for the removal and recovery of $\mathrm{PO}_{4}{ }^{3-}$ and $\mathrm{NH}_{4}{ }^{+}$from AnMBR permeate is a promising technology. Figure 7 illustrates how ion exchange-precipitation nutrient recovery may be implemented in a wastewater treatment operation downstream of AnMBR treatment to achieve a more sustainable operation using wastewater as a resource for recovery of both energy and nutrients. 


\section{ACKNOWLEDGments}

This project was supported by Xylem Corporation. The authors thank Dr. Matt Seib for operation of the AnMBR used to treat wastewater ahead of the ion exchange tests performed in this study. We also greatly appreciate Mr. Mike Dollhopf's assistance with ICP-MS analyses and Dr. Ray Fournelle's assistance with SEM and EDS.

\section{REFERENCES}

APHA; AWWA; WEF. (2012). Standard methods for the examination of water and wastewater, 22nd edn (E.W. Rice, R.B. Baird, A.D. Eaton \& RS Clesceri, Eds.). Washington D.C.: American Public Health Association, American Water Works Association, and Water Environment Federation.

de-Bashan, L. E., \& Bashan, Y. (2004). Recent advances in removing phosphorus from wastewater and its future use as fertilizer (1997-2003). Water Research, 38(19), 4222-4246.

Blaney, L. M., Cinar, S., \& SenGupta, A. K. (2007). Hybrid anion exchanger for trace phosphate removal from water and wastewater. Water Research, 41(7), 1603-1613.

Cordell, D., Rosemarin, A., Schröder, J. J., \& Smit, A. L. (2011). Towards global phosphorus security: A systems framework for phosphorus recovery and reuse options. Chemosphere, 84(6), 747-758.

Hao, X., Wang, C., van Loosdrecht, M. C. M., \& Hu, Y. (2013). Looking beyond struvite for P-recovery. Environmental Science and Technology, 47(10), 4965-4966.

Hedström, A. (2001). Ion exchange of ammonium in zeolites: A literature review. Journal of Environmental Engineering, 127(8), 673-681.

Le Corre, K. S., Valsami-Jones, E., Hobbs, P., \& Parsons, S. A. (2005) Impact of calcium on struvite crystal size, shape and purity. Journal of Crystal Growth, 283 (3-4), 514-522.
Mayer, B. K., Baker, L. A., Boyer, T. H., Drechsel, P., Gifford, M., Hanjra, M. A. Parameswaran, P., Stoltzfus, J., Westerhoff, P., \& Rittmann, B. E. (2016). Total value of phosphorus recovery. Environmental Science and Technology, 50(13), 6606-6620.

McCarty, P. L., Bae, J., \& Kim, J. (2011). Domestic wastewater treatment as a net energy producer-Can this be achieved? Environmental Science and Technology, 45(17), $7100-7106$.

Morse, G. K., Brett, S. W., Guy, J. A., \& Lester, J. N. (1998). Review: Phosphorus removal and recovery technologies. Science of the Total Environment, 212(1), 69-81.

Petruzzelli, D., Dell'Erba, A., Liberti, L., Notarnicola, M., \& Sengupta, A. K. (2004). A phosphate-selective sorbent for the REM NUT process: Field experience at Massafra Wastewater Treatment Plant. Reactive \& Functional Polymers, 60, 195-202.

Rittmann, B. E., Mayer, B., Westerhoff, P., \& Edwards, M. (2011). Capturing the lost phosphorus. Chemosphere, 84(6), 846-853.

Seib, M. D., Berg, K. J., \& Zitomer, D. H. (2016). Low energy anaerobic membrane bioreactor for municipal wastewater treatment. Journal of Membrane Science, 514, $450-457$.

Sengupta, S. (2013). Macronutrient removal and recovery from tertiary treatment of wastewater. Nov. Solut. Water Pollution, 1123, 167-187.

Sengupta, S., \& Pandit, A. (2011). Selective removal of phosphorus from wastewater com bined with its recovery as a solid-phase fertilizer. Water Research, 45(11), 3318-3330.

Speece, R. E. (2008). Anaerobic biotechnology and odor/corrosion control for municipalities and industries. Nashville, TN: Archae Press.

Williams, A. T. (2013) Ion exchange nutrient recovery from municipal wastewater. M.S.Thesis, Marquette University.

Williams, A. T., \& Mayer, B. K. (2013). Advancements in ion exchange processes for municipal wastewater nutrient recovery. Chicago, IL: Proc. Water Environ. Fed. Tech. Exhib. Conf.

Williams, A. T., Zitomer, D. H., \& Mayer, B. K. (2015). Ion exchange-precipitation for nutrient recovery from dilute wastewater. Environmental Science: Water Research \& Technology, 1(6), 832-838.

Zhao, D., \& Sengupta, A. K. (1998). Ultimate removal of phosphate from wastewater using a new class of polymeric ion exchangers. Water Research, 32(5), 1613-1625. 